\title{
Material Issues for Nanoporous Ultra Low-k Dielectrics
}

\author{
Kookheon Char, Bong Jun Cha and Suhan Kim \\ 1 \\ School of Chemical Engineering, Seoul National University, Seoul 151-744, Korea
}

\begin{abstract}
Using the molecularly designed porogen (pore generating agent) approach, novel nanoporous low-k materials with improved mechanical properties have been achieved based on poly(methylsilsesquioxane), PMSSQ, structure. Two different methods, microphase separation system and grafted porogen system, were adopted to realize nonporous ultra low-k dielectrics with superior mechanical properties. We found that the behavior of dielectric constant as well as thin film modulus depends on the molecular structure of a porogen. Within the decomposition temperature windows of grafted porogens, a low-k material with $\mathrm{k}<2.2$ and Young's modulus $>6$ $\mathrm{GPa}$ was achieved. These results indicate that it is possible to design and fabricate nanoporous thin films with balanced low dielectric constant and robust mechanical properties, which are highly desired for microelectronic industry.
\end{abstract}

\section{Introduction}

Since low-k dielectrics have been regarded as a necessary choice to elevate IC (integrated circuit) performance for next generation integration technology, tremendous efforts worldwide have been devoted to the development of low-k materials with $\mathrm{k}<2.8 \sim 3.0$ that are targeted for the $130 \mathrm{~nm}$ device technology. ${ }^{1}$ The International Technology Roadmap (ITRS) anticipates that low-k dielectrics below 2.5 for the $90 \mathrm{~nm}$ node should soon be lowered to 2.0 or less for the future technology node by 2010 . The dielectric constant of a given material can be continuously lowered by introducing porogens, leaving behind air-filled nanopores $(\mathrm{k} \sim 1)$, into insulating films. A variety of pore generation methods have been utilized to create ultra low-k $(k<2.2)$ dielectrics with $\mathrm{k}$ value as low as $1.5^{2-8}$ However, the choice of low-k material that can meet the integration and reliability requirements ${ }^{9}$, while still maintaining the low $\mathrm{k}$ value, remains elusive because of fundamental material limitations of nanoporous low- $k$ dielectrics originate from the reduced density. Consequently, the design strategy for low-k materials to have balanced electrical (low k) and mechanical (high E) properties becomes increasingly necessary. In present study, we show a few examples in ultra low-k $(k<2.2)$ materials employing a variety of porogen molecular structures.

Sample Preparation

a. Microphase separation system
MSSQ:BTMSE copolymer, which is used as a matrix material, was prepared by the addition of $10 \mathrm{~mol} \%$ "bridged" BTMSE monomers to methyltrimethoxysilane (MTMS). A star-shaped aliphatic core porogen, a Tetronic (150R1, BASF) block copolymer and a modified Gemini surfactant are employed as pore generating polymers (porogens) and chemical structures are shown in figure 1 . The copolymer matrix precursor was mixed with 10,20 , and 30 wt. $\%$ porogen in methyl isobutyl ketone (MIBK) or 1-butanol. Solution was spun cast at $3000 \mathrm{rpm}$ for 30 seconds. Films prepared by the aliphatic porogens were cured under nitrogen at $420^{\circ} \mathrm{C}$ for 1 hour while other films were cured at $450{ }^{\circ} \mathrm{C}$ under $\mathrm{N}_{2}$ atmosphere.
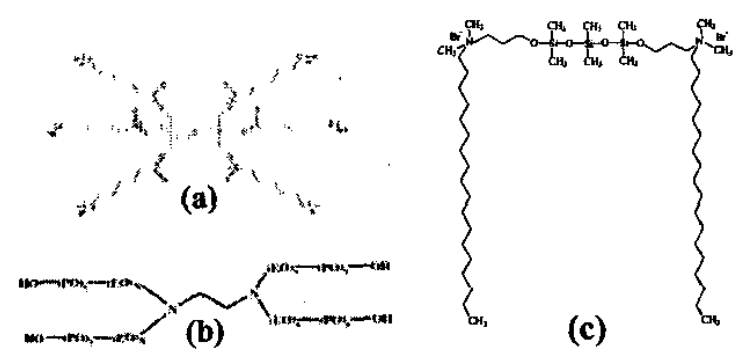

Fig. 1 Pore generating polymers: (a) aliphatic core porogen, (b) Tetronic, and (c) modified Gemini surfactant.

b. Grafted porogen system

A variety of monomers containing pore generating moieties were initially prepared by first the synthesis of porogen moieties and then the graft of the porogen moiety to alkoxy silanes by hydrosilylation and were subsequently copolymerized with methyltrimethoxysilane (MTMS) and/or 1,2 bistrimethoxysilylethane (BTMSE) to yield polymers denoted as $\boldsymbol{A}, \boldsymbol{B}$, and $\boldsymbol{T}$. For $\boldsymbol{A}$, porogen moieties were grafted to the MSSQ backbone and bridged BTMSE is introduced in the case of $T$. On the other hand, porogen moiety in $B$ was linked to the silane backbone by two covalent bonds. All the prepared polymers are readily spun cast and their molecular weights were confirmed by GPC. 'H NMR spectra also confirmed that $\boldsymbol{A}, \boldsymbol{B}$, and $\boldsymbol{T}$ polymers contain $8,13,10 \mathrm{~mole} \%$ of porogens, respectively.

\section{Results and Discussion}

a. Microphase separation system

Refractive indices of porous films gradually decrease with the porogen loading for the three types of porogens 
tested. Volume fraction porosities of the films are calculated by the Lorent-Lorentz equation:

$$
\frac{n^{2}-1}{n^{2}+2}=(1-\phi) \frac{n_{0}^{2}-1}{n_{0}^{2}+2}
$$

where, $n_{0}$ is the measured refractive index of the matrix material, and, $n$ is the measured refractive index of the nanoporous film. Figure 1 shows refractive index and volume fraction porosity as a function of porogen loading. It is noted that Tetronic porogens yield the highest porosity at a given porogen loading.
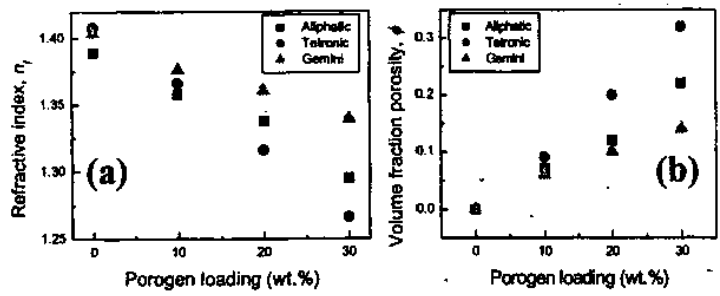

Fig. 2 Refractive index (a) and volume fraction porosity (b) of nanoporous films.

FT-IR spectra of porous films with different types of porogens are shown in figure 2 . The $\mathrm{Si}-\mathrm{O}-\mathrm{Si}$ network peak at $1030 \mathrm{~cm}^{-1}$, normalized with film thickness and porosity, decreases with the porogen loading in the case of aliphatic porogen. The relative ratio of the $\mathrm{Si}-\mathrm{O}-\mathrm{Si}$ networking peak at $1030 \mathrm{~cm}^{-1}$ to the Si-O-Si cage peak at $1130 \mathrm{~cm}^{-1}$ also clearly decreases with the addition of aliphatic porogen.
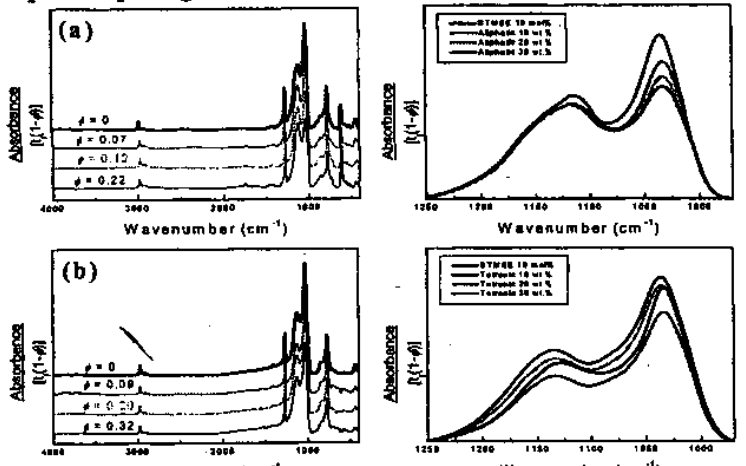

Wavenumber $\left(\mathrm{cm}^{-1}\right)$

Wovenumber (cm $\mathrm{m}^{-1}$ )
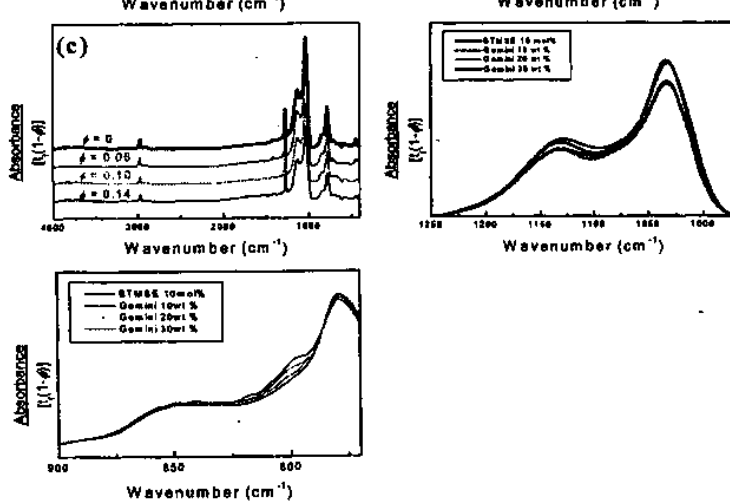

Fig. 3 FT-IR spectra of porous films prepared by (a) aliphatic porogens, (b) Tetronics, and (c) modified Gemini surfactant after curing.
On the other hand, Tetronic block copolymer and modified Gemini surfactant do not seem to disturb the matrix condensation: the relative ratio of the $\mathrm{Si}-\mathrm{O}-\mathrm{Si}$ network peak to the Si-O-Si cage peak does not change significantly. The $\mathrm{Si}-\left(\mathrm{CH}_{3}\right)_{2}$ peak at $800 \mathrm{~cm}^{-1}$ was also observed for the films prepared by the modified Gemini surfactants. It is also observed that this peak at $800 \mathrm{~cm}^{-1}$ increases with the loading of modified Gemini surfactant. This implies that the siloxane groups on the modified Gemini surfactant recombine with matrix.

Table 1. Electrical and mechanical properties of porous films prepared by (a) aliphatic porogens, (b) Tetronics, and (c) modified Gemini surfactants

\begin{tabular}{|c|c|c|c|c|}
\hline (a) & $\begin{array}{l}\text { Modulus } \\
\text { (GPa) }\end{array}$ & $\begin{array}{c}\text { Hardness } \\
\text { (GPa) }\end{array}$ & k-value & Porosity \\
\hline 0 & $7.53 \pm 0.06$ & $1.33 \pm 0.06$ & 2.86 & 0 \\
\hline 10 & $4.46 \pm 0.13$ & $0.78 \pm 0.04$ & 2.63 & 0.07 \\
\hline 20 & $3.15 \pm 0.13$ & $0.51 \pm 0.04$ & 2.42 & 0.12 \\
\hline 30. & $2.14 \pm 0.13$ & $0.33 \pm 0.02$ & 2.21 & 0.22 \\
\hline (b) & $\begin{array}{c}\text { Modulus } \\
\text { (GPa) }\end{array}$ & $\begin{array}{c}\text { Hardness } \\
\text { (GPa) }\end{array}$ & k-value & Porosity \\
\hline 0 & $8.16 \pm 0.10$ & $1.21 \pm 0.02$ & 2.82 & 0 \\
\hline 10 & $6.12 \pm 0.08$ & $0.88 \pm 0.02$ & 2.71 & 0.09 \\
\hline 20 & $4.20 \pm 0.05$ & $0.58 \pm 0.02$ & 2.48 & 0.20 \\
\hline 30 & $2.45 \pm 0.06$ & $0.36 \pm 0.01$ & 2.08 & 0.32 \\
\hline (c) & $\begin{array}{c}\text { Modulus } \\
\text { (GPa) }\end{array}$ & $\begin{array}{l}\text { Hardness } \\
\text { (GPa) }\end{array}$ & k-value & Porosity \\
\hline 0 & $7.88 \pm 0.13$ & $1.18 \pm 0.03$ & 2.80 & 0 \\
\hline 10 & $6.35 \pm 0.09$ & $0.91 \pm 0.03$ & 2.69 & 0.06 \\
\hline 20 & $4.63 \pm 0.11$ & $0.63 \pm 0.03$ & 2.43 & 0.10 \\
\hline 30 & $4.00 \pm 0.08$ & $0.54 \pm 0.02$ & 2.40 & 0.14 \\
\hline
\end{tabular}

The electrical and mechanical properties are listed in table 1. Aliphatic porogens yield low dielectric constants but show poor mechanical properties. Tetronic block copolymers, however, show low dielectric constant as well as acceptable mechanical properties.

Modified Gemini surfactant has the lowest porosity at a given porogen loading. At $20 \mathrm{wt} \%$ of loading, the modified Gemini surfactant sample has a lower dielectric constant and a higher modulus relative to the Tetronic porogens. This can be explained by the existence of possible interfacial reaction between siloxane groups in the surfactant and the matrix and the existence of Si$\left(\mathrm{CH}_{3}\right)_{2}$ in FT-IR probably lowers the polarity of the films resulting in films with low dielectric constants.

\section{b. Grafted porogen system}

Figure 4(a) shows the structural changes of a $B$ film measured with FT-IR after curing under $\mathrm{N}_{2}$ purge. Infrared spectra show that the peak intensity at $2910 \mathrm{~cm}^{-1}$ due to the asymmetric stretching of porogen groups notably decreases above $300^{\circ} \mathrm{C}$ together with the peak at $1514 \mathrm{~cm}^{-1}$ assigned to phenyl groups attached to the porogen moieties and these peaks almost disappear at $450{ }^{\circ} \mathrm{C}$. Upon curing, the absorption band at $1040 \mathrm{~cm}^{-1}$ increases due to the structural rearrangement from a 
cage-like symmetric $\mathrm{Si}-\mathrm{O}-\mathrm{Si}$ structure to an asymmetric $\mathrm{Si}-\mathrm{O}-\mathrm{Si}$ network structure, which is related to the formation of a more dense film structure.

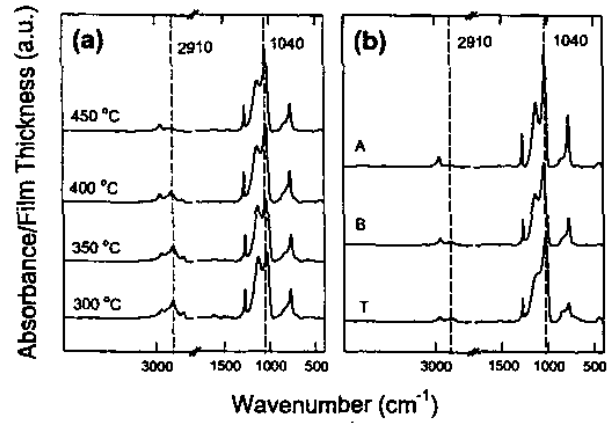

Fig. 4 FT-IR spectra showing the structural changes of $B$ film with temperature (a) and $\mathrm{A}, \mathrm{B}$, and $\mathrm{T}$ films after curing at $450^{\circ} \mathrm{C}$.

Figure 4 (b) shows infrared spectra of $A, B$, and $T$ films after curing at $450{ }^{\circ} \mathrm{C}$. For all the films tested, it is confirmed that the grafted porogens are almost removed. In addition, absorbance intensities at $1040 \mathrm{~cm}^{-1}$ in $B$ and $\boldsymbol{T}$ are stronger than that for $\boldsymbol{A}$. As a result, it is expected that thermal and mechanical stabilities of $B$ and $T$ are higher than that of $\boldsymbol{A}$ due to the formation of a dense film structure. Figure 5 shows the behavior of refractive index $\left(\mathrm{n}_{\mathrm{f}}\right)$ and dielectric constant $(\mathrm{k})$ for $\boldsymbol{B}$ with curing temperature. For all the films examined, $k$-values and refractive indices decrease with curing temperature due to the formation of porous structure by the decomposition of the grafted porogens and also the removal of silanol groups by polycondensation. $k$-values of $\boldsymbol{A}, \boldsymbol{B}$, and $\boldsymbol{T}$ reduce to $2.67,2.17$ and 2.12 after curing at $450{ }^{\circ} \mathrm{C}$, respectively. For $\boldsymbol{A}$, the $k$-value of 2.57 after curing at $400^{\circ} \mathrm{C}$ is lower than 2.67 at $450{ }^{\circ} \mathrm{C}$, signaling the possible collapse of pores in the films by the introduction of bulky free-rotating porogens. On the other hand, the collapse of pores was observed for $\boldsymbol{B}$ and $T$ samples. This observation supports the idea that the introduction of bridge-type comonomer such as BTMSE increases the thermomechanical stability of a film.

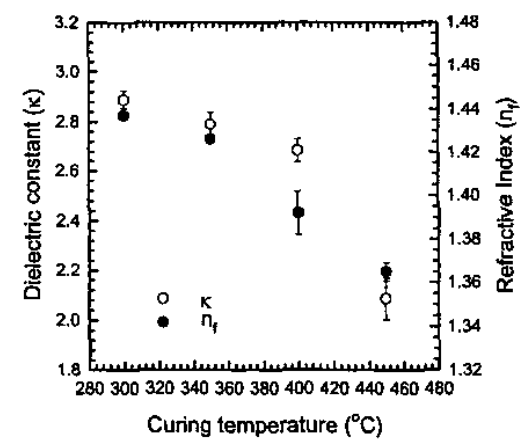

Fig. 5 The change of dielectric constant and refractive index with curing temperature for a $\mathrm{B}$ film.
Table 2 shows the mechanical properties for low-k materials with different molecular structures of grafted porogens. As mentioned earlier, the elastic modulus of A is lower than those of $\boldsymbol{B}$ and $\boldsymbol{T}$ after curing. On the other hand, $B$ and $T$ show moduli of $6.16 \mathrm{GPa}$ and $3.76 \mathrm{GPa}$ that are higher than $3.40 \mathrm{GPa}$ of non-porous PMSSQ in spite of the pore formation in the film as evidenced in the low $\mathrm{k}$ values. This is believed to be due to the high crosslinking density by the incorporation of bridged hexa-coordinated alkoxy groups and the possible formation of $\mathrm{SiO}_{2}$ structure by the dissociation of $\mathrm{Si}-\mathrm{C}$ bonds, respectively. The tetra-coordinated $\mathrm{SiO}_{2}$ structure is also confirmed by the ${ }^{29} \mathrm{Si}$ CP-MAS NMR spectra.

Table 2. Electrical and mechanical properties of porous films after

\begin{tabular}{cccc} 
curing & & & \\
\hline Film & Modulus (GPa) & Hardness (GPa) & k-value \\
\hline A & $2.71 \pm 0.05^{\mathrm{a}}$ & $0.32 \pm 0.01^{\mathrm{a}}$ & $2.57^{\mathrm{a}}$ \\
B & $6.16 \pm 0.10^{\mathrm{b}}$ & $0.75 \pm 0.02^{\mathrm{b}}$ & $2.17^{\mathrm{b}}$ \\
& & & \\
$\mathrm{T}$ & $3.76 \pm 0.06^{\mathrm{b}}$ & $0.49 \pm 0.01^{\mathrm{b}}$ & $2.12^{\mathrm{b}}$ \\
\hline
\end{tabular}

2.0 Measured for films cured at 400 and $450{ }^{\circ} \mathrm{C}$, respectively. Nanoindentation data were taken at a relative value of $50 \mathrm{~nm}$.

\section{Conclusion}

Nanoporous thin films were prepared two different methods; microphase separation system and grafted porogen system. Dielectric films with balanced low dielectric constant and mechanically superior properties were prepared by the decomposition of porogens chemically grafted to the organosilica matrix. The reduction of dielectric constant is achieved by the removal of grafted porogen moieties, while the increase in mechanical properties is due to the bridged hexacoordinated alkoxy groups and the additional partial conversion to the tetra-coordinated $\mathrm{Si}-\mathrm{O}$ bond after removal of the grafted porogens in the case of PMSSQ films containing a bridge-type comonomer.
Acknowledgement
The author would like to thank Prof. D. Y. Yoon, J.-K. Lee, and H.-W. Rhee for useful discussion. This work is supported by the Collaborative Project for Excellence in Basic System IC Technology. Financial supports from the Ministry of Science and Technology (MOST) (the National Research Laboratory Fund) and the Korean Ministry of Education through the Brain Korea 21 Program are also greatly acknowledged.
References
(1) L. Peters, Semiconductor International 2001, May.
(2) C. V. Nguyen, et al, Chem. Mater. 1999, 11,3080
(3) H. W. Ro, et al, Polym. Prep., 2002, 43(2), 1166.
4) H. W. Ro, et al, Polym. Prep., 2001, $42(2), 889$.
5) Y. Toivola, et al, J. Electrochem. Soc., 2004, 151,45 .
6) S. Mikoshiba, et al, J. Mater. Chem. 1999, 9, 591 .
(7) B. Zhong, et al, Polym. Mater. Sci. Eng. 2002, 87, 440.
(7) B. Zhong, et al, Polym. Mater. Sci. Eng. 2002, 87, 440.
(9) A. E. Braun, Semiconductor International 2003, May. 